\title{
A Clinical Study of New Onset Seizure Disorder in Peripartum Period
}

\author{
Firdushi Begum ${ }^{1}$, Arjun Roy Khakhlari², Papori Borah ${ }^{3}$ \\ ${ }^{1 *}$ Assistant Professor, Department of Biochemistry, ${ }^{2}$ Assistant Professor, Department of Anaesthesia, \\ ${ }^{3}$ Assistant Professor, Department of Neurology, Gauhati Medical College \& Hospital, Guwahati, Assam, INDIA.
}

\begin{abstract}
Introduction: Wide range of physiological changes that take place in a pregnant woman during pregnancy or in puerperium can precipitate new neurological disorders. Epilepsy is a common neurological disorder which complicate the peripartum period. This study was planned with an aim to study the clinical profile of new onset seizure disorders during the peripartum period.

Materials \& Methods: This prospective observational study was conducted in Gauhati Medical College \& Hospital for one year period in 2015. All cases of new onset seizure in peripartum period were clinically studied.

Results: Out of the 15,723 deliveries that took place during the study period, 134 women presented with new onset seizure in the peripartum period. Out of this $75.37 \%$ were diagnosed as eclampsia, $17.16 \%$ as stroke, tubercular meningitis and dyselectrolytemia was the cause in $2.73 \%$ each, and $1.49 \%$ of new onset seizure cases were suffering from encephalomyelitis and septic encephalopathy. Out of the 134 new onset seizure cases 126 presented with Generalized tonic clonic seizure.

Discussion: There are very few published data on new onset seizure during peripartum period. The findings of this study
\end{abstract}

\section{INTRODUCTION}

Identification and treatment of neurological disorders in women during the peripartum period present special challenges to the neurologist and other health providers. The range of neurological conditions affecting women of reproductive age is extremely broad.1,2 Neurological disorders are a significant cause of morbidity and mortality in peripartum period.

During pregnancy and the puerperium, women experience rapid physiological changes that can precipitate new neurologic or psychiatric symptoms. There are adaptations of virtually every maternal organ system to meet the demands of fetal development and birth. Modifications in neuroanatomy, reproductive endocrinology, systemic and cerebral circulation, coagulation profile and metabolism can predispose the onset or cause deterioration of various neurological disorders. The lack of knowledge is due to the fact that research on pregnant women is technically difficult, challenging, and highly regulated due to ethical concerns. Various neurological conditions found in pregnant women and during puerperium are epilepsy, eclampsia, facial nerve palsy, pituitary tumour, cerebrovascular disorders, myasthenia gravis, multiple sclerosis, peripheral neuropathy, intracerebral haemorrhage and cerebral venous thrombosis.

Epilepsy is a common neurological disorder which complicates the peripartum period. The major pregnancy related threats to women with epilepsy are increased seizure rates and risks for fetal points out to eclampsia as the major aetiological cause of new onset seizure followed by stroke. More such studies are required for a better understanding of new onset seizure disorder in the peripartum period.

Key words: Eclampsia, Generalized tonic clonic seizure, Puerperium, Seizure.

\section{*Correspondence to:}

Dr. Firdushi Begum, Assistant Professor, Department of Biochemistry, Gauhati Medical College \& Hospital, Guwahati-32, Assam, INDIA.

Email: firdushi72@gmail.com

Article History:

Received: 08-04-2016, Revised: 13-04-2016, Accepted: 20-04-2016

\begin{tabular}{|l|c|}
\hline \multicolumn{2}{|c|}{ Access this article online } \\
\hline $\begin{array}{l}\text { Website: } \\
\text { www.jimrp.com }\end{array}$ & Quick Response code \\
\hline DOI: & \\
10.21276/ijmrp.2016.2.3.032 & \\
\hline
\end{tabular}

malformations. Although earlier studies described a worsening of seizure activity during pregnancy, this is not so now because of better prenatal management. However women with epilepsy have a small increased risk of some pregnancy complications other than seizures (Harden and associates, 2009) ${ }^{3}$. Studies have shown an increased rate of caesarian delivery in women with epilepsy. Pre eclampsia, post-partum hemorrhage, and postpartum depression have also been found to increase. Finally children of mothers with epilepsy have a $10 \%$ risk of developing a seizure disorder.

Very few studies have been undertaken to know the extent of this problem of new onset seizure in peripartum period. More knowledge about this problem and its etiology will help us in taking preventive measures against it. With this motive in mind this study was planned.

\section{AIMS \& OBJECTIVES}

1. To study the clinical profile of new onset seizure disorders during peripartum period.

2. To investigate the etiological factors of this disorder.

\section{MATERIALS \& METHODS}

The study was planned as a prospective observational study. It was conducted in the department of Neurology, Gauhati Medical College \& Hospital from August 2012 to Novemeber, 2013. Cases 
were taken from the department Of O\&G, and Laboratory investigations done in Central Laboratory, $\mathrm{GMCH}$. Necessary approval of Institutional Ethical committee was obtained to conduct the study.

Selection of cases: Cases were selected from pregnant ladies attending O\&G OPD or Neurology OPD or admitted into the indoor wards of $O \& G$ and Neurology.

Inclusion Criteria

- Cases presenting with new onset seizure disorder in the peripartum period.

- Peripartum period includes last one month of gestational period continuing upto six weeks post-delivery.

\section{Exclusion Criteria}

- Cases with pre-existing seizure disorder were excluded from the study.

\section{Methodology}

A detailed history was taken of all the cases regarding nature, duration, progression of symptoms, socioeconomic history, detailed obstetrical and puerperium history, and noted down in a questionnaire. All cases were subjected to a thorough general and systemic examination with special importance to examination of the nervous system. All necessary investigations were done to evaluate the patient.

\section{Statistical Analysis}

All calculations were performed using the Microsoft excel program, 2007 edition. In the course of evaluation of the collected data, descriptive statistical methods (average, standard deviation), were used. Data was expressed as mean \pm SD.

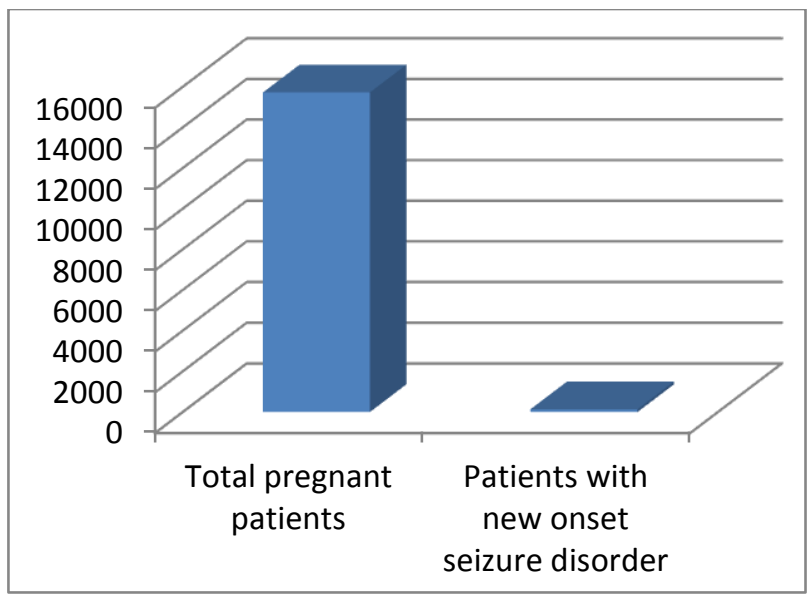

Fig 1: Showing the total number of pregnant patients with new onset seizure disorder.

Table 1: Demographic profile of patients with new onset seizure

\begin{tabular}{lc}
\hline Clinical Characteristics & New Onset Seizure \\
\hline Age (yr) & \\
Mean \pm SD & $24.06 \pm 4.913$ \\
$95 \% \mathrm{Cl}$ & $23.379-24.741$ \\
Range & $16-37$ \\
Parity & \\
Primigravida-no (\%) & $95(70.89)$ \\
Multigravida- no (\%) & $39(29.10)$ \\
Timing & \\
Antepartum no (\%) & $57(42.54)$ \\
Postpartum-no (\%) & $77(57.46)$ \\
\hline
\end{tabular}

Table 2: Etiological spectrum of patients with new onset seizure in peripartum period.

\begin{tabular}{lll}
\hline Neurological diagnosis & Number of cases & percentage \\
\hline Eclampsia & 101 & 75.37 \\
Stroke & 23 & 17.16 \\
Tubercular Meningitis & 3 & 2.23 \\
Encephalomyelitis & 2 & 1.49 \\
Septic encephalopathy & 2 & 1.49 \\
Dyselectrolytemia & 3 & 2.23 \\
\hline
\end{tabular}

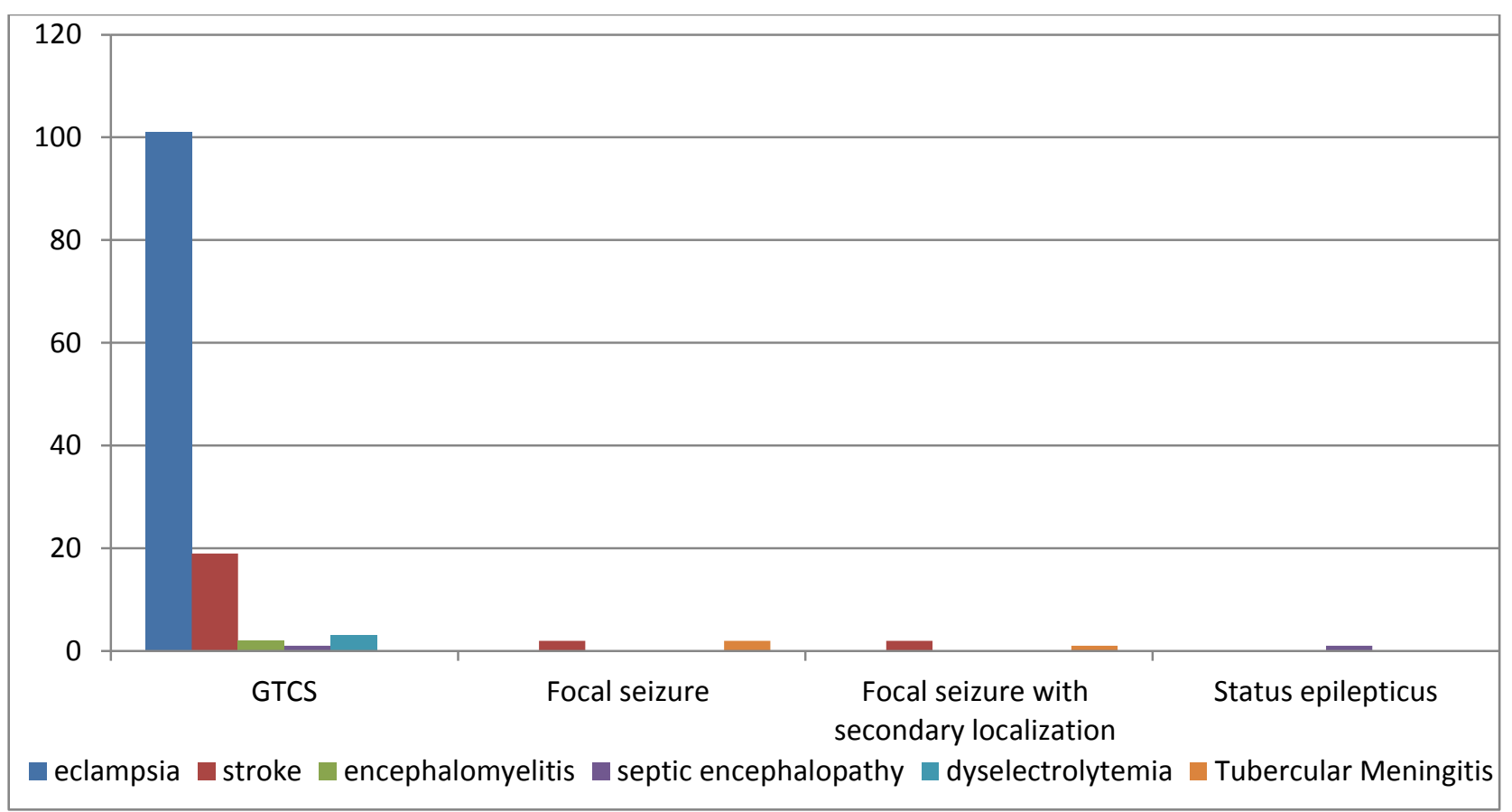

Fig 2: Distribution of seizure seismology according to etiology. 
Table 3: Distribution of Seizure Seismology according to etiology.

\begin{tabular}{lcccc}
\hline Etiology & GTCS & Focal seizure & FS with sec generalization & Status Epilepticus \\
\hline Eclampsia & 101 & 0 & 0 & 0 \\
Stroke & 19 & 2 & 2 & 0 \\
Encephalomyelitis & 2 & 0 & 0 & 0 \\
Septic encephalopathy & 1 & 0 & 0 & 1 \\
Dyselectrolytemia & 3 & 0 & 0 & 0 \\
Tubercular meningitis & 0 & 2 & 1 & 0 \\
\hline
\end{tabular}

Table 4: Demographic profile of patients with eclampsia

\begin{tabular}{ll}
\hline Clinical Characteristics & Eclampsia \\
\hline Age(yr) & \\
Mean \pm SD & $23.356 \pm 4.78$ \\
$95 \% \mathrm{Cl}$ & $22.471-24.242$ \\
Range & $17-37$ \\
Parity & \\
Primigravida-no(\%) & $85(84.16)$ \\
Multigravida- no(\%) & $16(15.84)$ \\
Timing & \\
Antepartum no(\%) & $43(42.57)$ \\
Postpartum-no(\%) & $58(57.43)$ \\
\hline
\end{tabular}

\section{RESULTS \& DISCUSSION}

Gauhati Medical College \& Hospital is a tertiary care centre for Neurology, Neurosurgery and obstetrics services. Out of 15,723 deliveries during the study period, 134 presented with new onset seizure. Seizure and epilepsy in pregnancy has been studied extensively. 4,5 The findings of one study showed that structural and metabolic changes may precipitate new-onset seizures during pregnancy. ${ }^{4}$ The structural causes include intracranial hemorrhage of multiple types, cerebral venous sinus thrombosis and ischemic stroke. Metabolic causes include hyperemesis gravidarum, acute hepatitis (fatty liver of pregnancy, or viral hepatitis); acute intermittent porphyria, and infections such as malaria, and most important is eclampsia.

There are very few published data on new-onset seizures during the peripartum period. In this study the incidence of new onset seizure disorder was found to be 852 per 100,000 deliveries. Of them $42.54 \%$ presented before delivery while $57.46 \%$ presented in the postpartum period. Of the new onset seizures $94.03 \%$ presented with GTCS, $2.98 \%$ with focal seizure,2.24\% focal seizure with secondary generalization and only 1 patient presented with status epilepticus. The findings are very much similar to the study conducted by Gupta et $\mathrm{al}^{5}$, where they found that $77.27 \%, 9.09 \%$ and $13.63 \%$ presented with GTCS, focal seizure and focal seizure with secondary generalization respectively. But in that study, cases of eclampsia were totally excluded and patients with pre-existing neurological disorders included. So their study does not represent true incidence of new onset seizure in pregnancy. One patient $(0.746 \%)$ presented with status epilepticus in our study, whereas Gupta et al ${ }^{6}$ reported that 7 patients $(31.82 \%)$ had status epilepticus. Significantly greater number of patients presented with status epilepticus in that study ${ }^{6}$ in comparison to other studies ( $31.8 \%$ vs. 0.53 to $5.3 \%$ ) probably due to the inclusion of known cases of epilepsy.

Pre eclampsia is a complication of pregnancy that affects approximately $6 \%$ to $8 \%$ of pregnancies in developed nations ${ }^{7}$.
It is a clinical syndrome defined by gestational hypertension and proteinuria which generally comes after the $20^{\text {th }}$ week of pregnancy. Eclampsia is traditionally defined as the addition of new onset seizures and/or coma during pregnancy, labour, or puerperium, in the setting of preeclampsia. However seizures often occur in the absence of pre-eclamsia syndrome, particularly in late postpartum eclampsia ${ }^{8}$.

Although many studies regarding etiological spectrum of neurological disease during pregnancy was carried out in India, they have not included eclampsia in their patient population.6,9-11 The incidence of eclampsia reported by Singh et al ${ }^{12}$ is $3.2 \%$, $82.27 \%$ were primigravida and $18.4 \%$ presented during postpartum period. A study conducted at Hong-Kong ${ }^{13}$, reported an incidence of eclampsia as 39 per 1,00,000 pregnancies but no data regarding the parity status or timing of presentation was reported. The mean age and parity status of eclamptic patients in our study correlates well with the studies by Singh et al ${ }^{12}$ and AlHayali et $a^{14}$. But in these two studies maximum patients presented during antepartum period, whereas we observed maximum incidence during postpartum period. Al hayali RM et al included women with acute deterioration of conscious level with or without convulsions or focal neurological signs who were diagnosed with eclampsia and admitted to a critical care unit in Iraq. The mean age with SD of their population was $23.47 \pm 5.32$ years with $85 \%$ primigravida and $15 \%$ presented during antepartum period. In the present study, in $75.37 \%$ of women presenting with new onset seizure, eclampsia was found to be the cause. The incidence of eclampsia was 642.37 per $1,00,000$ deliveries. The timing of presentation of eclampsia was mostly postpartum (57.43\%) followed by antepartum (42.57\%).

All of these patients suffering from eclampsia presented with GTCS. $23(17.16 \%)$ women with new onset seizure were diagnosed with stroke and $82.61 \%$ of them presented with GTCS. In $2.24 \%$ of patients presenting with new onset seizure dyselectrolytemia was found to be the cause. All of them presented with GTCS. In neuro imaging, we have found features suggestive of hypertensive encephalopathy/Posterior Reversible Encephalopathy Syndrome (PRES) and cerebral edema in all patients with eclampsia.

\section{CONCLUSION}

Neurological disorders are an important cause of morbidity and mortality in the reproductive age group. The most common cause of new onset seizure in this study was found to be eclampsia followed by stroke. There are very few studies which have dealt with new onset seizure in the peripartum period. For a clearer picture more studies need to be conducted. This will help us in the proper understanding of the problem which will in turn go a long way in helping us to think of and devise new approaches for its prevention and cure. 


\section{REFERENCES}

1. Gold Smith PJ. Neurological disorders of pregnancy, New York: Future Publishing 1986.

2. Donaldson Jo. Neurology of Pregnancy.2nd Edition, London Saunders, 1989.

3. Harden CL, Hopp J, Ting TY, et al. Practice parameter update: Management issues for women with epilepsy-focus on pregnancy (an evidence based review): Obstetrical complications and change in seizure frequency: Report of the Quality Standards Sub-Committee of the American Academy of Neurology and American Epilepsy Society. Neurology. 2009. July 14;73 (2):126-32

4. Thomas SV, Yam U, Devi JS. Predictors of seizure during pregnancyin women with epilepsy.Epilepsia. 2012; 53(5):85-88.

5. Beach RL, Kaplan PW. Seizures in pregnancy: diagnosis and management. Int Rev Neurobiol. 2008; 83:259-71.

6. Gupta S, Rohatgi A, Sharma SK, Gurtoo A. A study of neurological disorders during pregnancy and puererium. Annals of Indian Academy of Neurology. 2006; 9(3):152-157.

7. ACOG practice bulletin Diagnosis and management of preeclampsia and eclampsia. Number 33, January 2002. Obstet Gynecol. 2002;99(1):159-167 [PubMed]

8. Aagaard-Tillery KM, Belfort MA. Eclampsia: morbidity, mortality, and management. Clin Obstet Gynecol. 2005;48(1):12-23 [PubMed] 9. Janaki S, Thomas L. Neurological complications in pregnancy and puerperium. Neurol India 1963; 11:128-37.

10. Agarwal K. Neurological disorders in pregnancy and puerperium. J Assoc Phys India 1968; 19:705-13.
11. Srinivasan K, Ramamurthi B. Neurological disorders in pregnancy and puerperium. J Assoc Phys India .1971; 19:705-13.

12. S Singh, A Behera. Eclampsia In Eastern India: Incidence, Demographic Profile And Response To Three Different Anticonvulsant Regimes Of Magnesium Sulphate. The Internet Journal of Gynecology and Obstetrics. 2010 Volume 15 Number 2. (http://ispub.com/lJGO/15/2/7708)

13. To WK, Cheung RT. Neurological Disorders in Pregnancy. Hong Kong Med J. 1997; 3:400-8.

14. Rami M, Al Hayali RM, Dhaher J, Al Haboo, Mohammed K Hammo. Peripartum neurological emergencies in a critical care unit. Neurosciences.2008; 13(2):155-160.

\section{Source of Support: Nil. Conflict of Interest: None Declared.}

Copyright: (c) the author(s) and publisher. IJMRP is an official publication of Ibn Sina Academy of Medieval Medicine \& Sciences, registered in 2001 under Indian Trusts Act, 1882.

This is an open access article distributed under the terms of the Creative Commons Attribution Non-commercial License, which permits unrestricted non-commercial use, distribution, and reproduction in any medium, provided the original work is properly cited.

Cite this article as: Firdushi Begum, Arjun Roy Khakhlari, Papori Borah. A Clinical Study of New Onset Seizure Disorder in Peripartum Period. Int J Med Res Prof. 2016; 2(3):147-50. 